\title{
Response of ascorbic acid content and acidity to different storage temperatures and durations in oranges
}

Ijaz Hussain ${ }^{1 *}$, Abdur Rab ${ }^{2}$, Shah Masaud Khan ${ }^{1}$, Khalid Naveed ${ }^{1}$, Sardar Ali ${ }^{1}$, Izhar Hussain ${ }^{1}$, Muhmamad Sajid ${ }^{3}$ and Asif ur Rehman $\mathrm{Khan}^{4}$

1. Department of Agricultural Sciences, University of Haripur-Pakistan

2. Department of Horticulture, Khyber Pakhtunkhwa Agriculture University, Peshawar-Pakistan

3. Department of Agriculture, Hazara University, Mansehra-Pakistan

4 Hazara Agriculture Research Station, Abbottabad-Pakistan

*Corresponding author's email: ijazhorticulturist@gmail.com

Citation

Ijaz Hussain, Abdur Rab, Shah Masaud Khan, Khalid Naveed, Sardar Ali, Izhar Hussain, Muhmamad Sajid and Asif ur Rehman Khan.Response of ascorbic acid content and acidity to different storage temperatures and durations in oranges. Pure and Applied Biology. Vol. 6, Issue 1, pp304-309. http://dx.doi.org/10.19045/bspab.2017.60028

\begin{tabular}{llll}
\hline \hline Received: 23/11/2016 & Revised: 21/02/2017 & Accepted: 26/02/2017 & Online First: 28/02/2017 \\
\hline \hline
\end{tabular}

\section{Abstract}

Oranges were kept at ambient condition $\left(20 \pm 2^{\circ} \mathrm{C}\right), 2^{\circ} \mathrm{C}, 6^{\circ} \mathrm{C}$ and $10^{\circ} \mathrm{C}$ for $0,15,30,45$ and 60 days, respectively. Mean percent difference in each interval was calculated and analyzed. Highest decease in ascorbic acid content $(1.24 \mathrm{mg} / 100 \mathrm{ml})$ was observed at 60 days in room temperature followed significantly $(0.68 \mathrm{mg} / 100 \mathrm{ml})$ at $2^{\circ} \mathrm{C}$ in same storage period whereas lowest reduction of $.02 \mathrm{mg} / 100 \mathrm{ml}$ was witnessed in zero storage period plus SMT (SMT stands for What?) at $2^{\circ} \mathrm{C}$. The highest reduction in acidity $(0.47 \%$ ) was recorded at room temperature after 60 days storage significantly followed by $(0.42 \%)$ at $2{ }^{\circ} \mathrm{C}$ in same storage period while it was lowest $(0.03 \%)$ at $2^{\circ} \mathrm{C}$ in zero storage duration with additional 72 hours of SM (?) followed non-significantly (0.04 $\%$ ) in room temperature having same storage period. The mean percent reduction in acidity was more at higher temperatures during storage whereas the percent acidity reduction was more at lower storage temperatures during shelf life of sweet orange fruits. The highest decline in acidity in sweet orange fruits stored at $2^{\circ} \mathrm{C}$ after 72 hours of simulated marketing is a manifestation of the chilling injury. It was observed that in cold storage conditions the oranges could be kept for 45 days. Beyond this, the quality deteriorates resulting chilling injury, however, at $10^{\circ} \mathrm{C}$ the oranges can be kept for longer durations.

Keywords: Citrus; Chilling injury; Ascorbic acid; Acidity; Storage

\section{Introduction}

Fruits and vegetables provide more than 90

$\%$ of the Vit $\mathrm{C}$ in human diets [1]. Citrus are the most important sources of vitamin $\mathrm{C}$. It is consumed in large quantities. Citrus fruits are sources of important nutrients for human health, including ascorbic acid, dietary fiber, phenolic compounds and phenolic acids [2, 3].Blood orange is an important variety of the world having valuable medicinal and nutritional compounds and is primarily cultivated in the Mediterranean climate 
[4].The major antioxidant components of blood orange (cv. Tarocco) juices are ascorbic acid, flavonoids and hydroxcinnmics acids [5-7].There is citrus market glut in Pakistan (December to April) which increases the post-harvest losses which are about 35-40\% [8]. Post-harvest losses in citrus fruits have been observed too much due to which fruit loses its quality [9]. Cold storage prolongs the post- harvest duration but has disadvantage as the cold storage temperature depends on the nature and type of fruit to be stored. Majority of storages at national level are being operated below $10^{\circ} \mathrm{C}$. Thus, the stored produce quality is adversely affected due to injury caused by chilling and loss of water from the commodity. The temperature of storage is the main aspect influencing the post-harvest deterioration scale of commodities [10]. Food nutritional quality in storage has become serious issue. The loss of nutrients (ascorbic acid/Vitamin C) might be a significant issue for the shelf life of citrus juice concentrates. Vitamin C content of citrus juices adversely affected during storage. Cold storages are used to prolong post-harvest life thereby making fruits more prone to chilling injury development and post-harvest rind disorders. These disorders cause severe financial losses to the citrus industry globally [11].Postharvest handling of oranges like long storage periods, storage at increased temperatures, physical and chilling injury are known to cause vitamin $\mathrm{C}$ loss in citrus. The main limiting factor of nutritional quality of fruits and vegetables is the loss of Ascorbic Acid and Carotenes. Decline in malic acid, acidity, reduction in ascorbic acid and significant change in sugars were observed during apple fruits storage. Postharvest losses of tropical fruits are a serious problem because of repaid deterioration during handling, transport and storage. Storage temperature was the prime limiting factor for the shelf life of citrus fruits [12]. Previously storage temperatures were studied in terms of their effects on chilling injury and physical damages occurred to the fruit commodities. Therefore, the study was undertaken to evaluate the effect of different storage temperatures and durations on percent ascorbic acid content, which is one the most important nutritional constituent of sweet orange.

\section{Materials and methods}

Sweet oranges (Blood Red) were procured from an orchard in Khaal Rabat area of District Dir, Khyber Pakhtunkhwa, Pakistan. The fruits having uniform maturity and size were grouped to curtail error and were stored in different storage conditions e.g. Ambient condition (Room Temperature), $2{ }^{\circ} \mathrm{C}, 6{ }^{\circ} \mathrm{C}$ and $10^{\circ} \mathrm{C}$ for different storage durations e.g. $0,15,30,45$ and 60 days. Sweet orange fruits were taken out of each storage interval and were analyzed for ascorbic acid content and acidity. At each storage interval, the fruits were taken out of storage and the immediate data was recorded. After taking the immediate data fruits were kept at room temperature for additional 72 hours of Simulated Marketing Time (SMT) and again analyzed for ascorbic acid content and acidity.

Ascorbic acid and acidity were determined by the standard method as mentioned in AOAC 1990 [13]. Mean percent difference between before and after SMT in Ascorbic Acid Content and Acidity was calculated and analyzed.

\section{Statistical analysis}

The ANOVA technique was applied to find the treatments and interactions differences. The means were further analyzed by using Least Significant Difference (LSD) Test, in cases where the differences were significant. For computing the ANOVA and LSD the Statistix 8.1 software was used.

\section{Results and discussion Ascorbic acid (mg/100 ml)}


Different temperatures, durations and their interaction had significant effect on decrease in ascorbic acid during shelf life of sweet orange fruits (Table 1). The decrease in ascorbic acid of the stored sweet orange fruits climbed significantly from the lowest $(0.04$ $\mathrm{mg} / 100 \mathrm{ml}$ ) at time zero in shelf life to the highest decrease of $0.65 \mathrm{mg} / 100 \mathrm{ml}$ at the end of storage period (60 days). In different storage temperatures, the highest reduction of $0.45 \mathrm{mg} / 100 \mathrm{ml}$ was recorded in room temperature followed significantly by 0.22 $\mathrm{mg} / 100 \mathrm{ml}$ at $2{ }^{\circ} \mathrm{C}$ whereas lowest reduction of $0.15 \mathrm{mg} / 100 \mathrm{ml}$ was noticed at $10{ }^{\circ} \mathrm{C}$ followed non-significantly by $0.17 \mathrm{mg} / 100$ $\mathrm{ml}$ at $6{ }^{\circ} \mathrm{C}$. Interactive effect was highest $(1.24 \mathrm{mg} / 100 \mathrm{ml})$ at 60 days in room temperature followed significantly $(0.68$ $\mathrm{mg} / 100 \mathrm{ml}$ ) at $2{ }^{\circ} \mathrm{C}$ in same storage period whereas lowest reduction of $0.02 \mathrm{mg} / 100 \mathrm{ml}$ was witnessed in zero storage period plus SMT at $2{ }^{\circ} \mathrm{C}$ (Figure 1). During storage, fruits lose weight, shrivel and change colour, lose acidity and ascorbic acid but gain sweetness [14]. Studies were conducted to assess the changes in ascorbic acid content of lemon fruits stored in zero energy cool chamber and under ambient atmosphere. It was concluded that the ascorbic acid of the fruits followed a decreasing trend in both the storage conditions; however, the decrease was comparatively very low in the fruits stored in zero energy cool chambers in comparison to the fruits stored under ambient conditions [15].The higher retention of the ascorbic acid in zero energy cool chambers might be due to the low temperature and respiratory rate resulting in the slow oxidation process, which helps in reducing the rate of conversion of ascorbic acid to dehydro ascorbic acid [16].

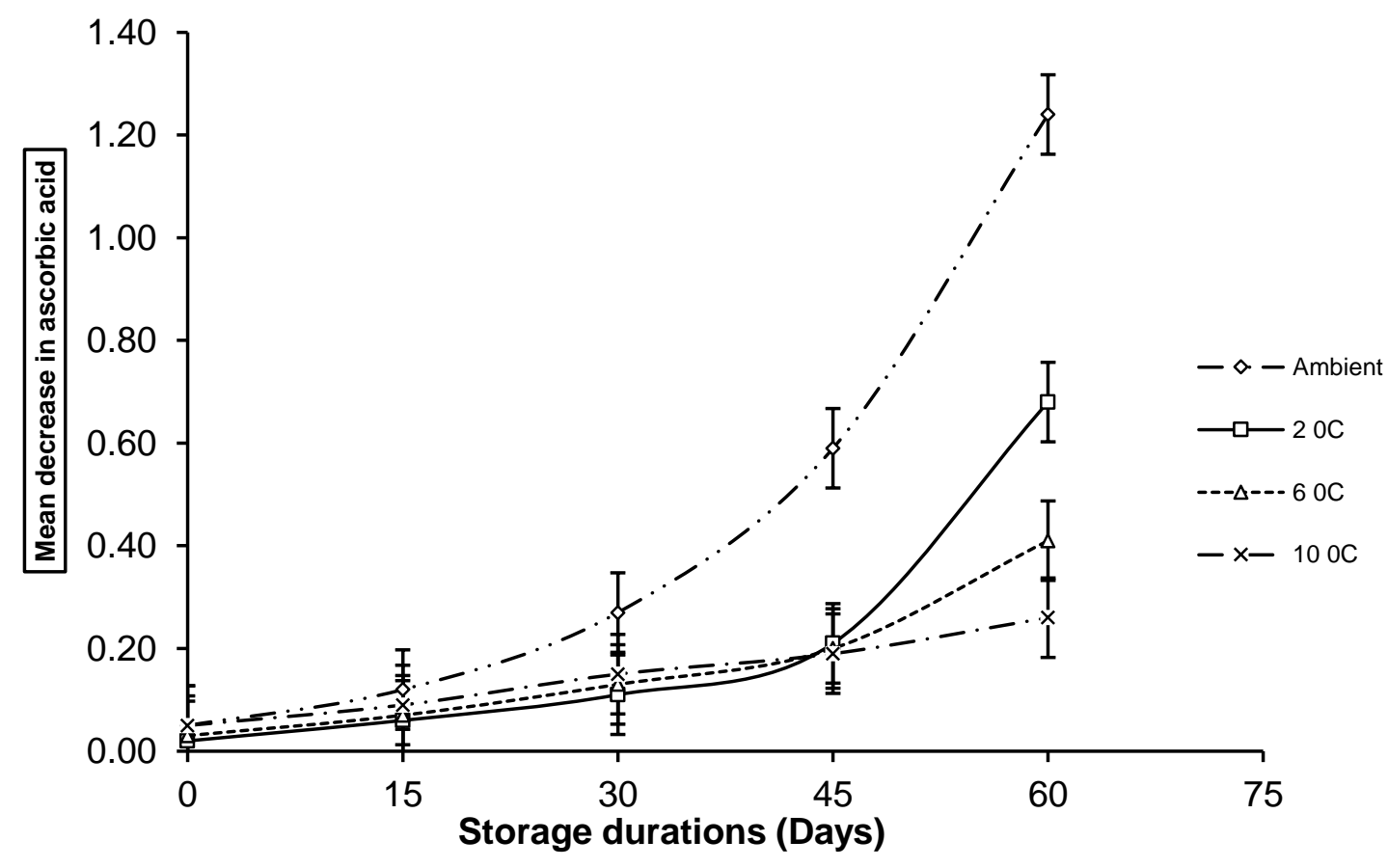

Figure 1. Mean decrease in Ascorbic Acid content of oranges affected by different storage durations and temperatures during shelf life

\section{Percent acidity}

Different storage temperatures, durations and their interaction had significant effect on percent decrease in acidity during shelf life of 
sweet orange fruits (Table 1). Highest reduction of $0.35 \%$ was observed at end of storage (60 days) significantly followed by $0.20 \%$ at 45 days storage duration while lowest reduction of $0.04 \%$ in acidity was found at zero storage period after 72 hours of simulated marketing. Percent decrease in acidity varied significantly in sweet orange fruits stored at different temperatures. Highest significant reduction of $0.20 \%$ was noted in room temperature followed significantly by $0.17 \%$ at $2{ }^{\circ} \mathrm{C}$ while lowest significant reduction of $0.12 \%$ was recorded at $10^{\circ} \mathrm{C}$ significantly followed by $0.15 \%$ at $6^{\circ} \mathrm{C}$. Interactive effect was highest $(0.47 \%)$ in room temperature in 60 days storage period followed significantly by $(0.42 \%)$ at $2^{\circ} \mathrm{C}$ in same storage period while it was lowest $(0.03 \%)$ at $2^{\circ} \mathrm{C}$ in zero storage duration with additional 72 hours of SM followed non-significantly $(0.04 \%)$ in room temperature having same storage period
(Figure 2). Percent acidity in sweet orange fruits stored at different temperatures in cold storage exhibited pattern of decrease in both during storage and shelf life. Nevertheless, the mean percent reduction in acidity was more at higher temperatures during storage whereas the percent acidity reduction was more at lower storage temperatures during shelf life of sweet orange fruits. The highest decline in acidity in sweet orange fruits stored at $2{ }^{\circ} \mathrm{C}$ after 72 hours of simulated marketing is a manifestation of the chilling injury. Increased activity of citric acid during ripening or reduction in acidity may be due to their conversion into sugars and further utilization in the metabolic processes of fruits [16].The reduction in titratable acidity might be due to utilization of citric acid and malic acid in the fruit respiratory process. Fruits lose weight, shrink, change colour, drop acidity and ascorbic acid but gain sweetness during storage $[17,18]$.

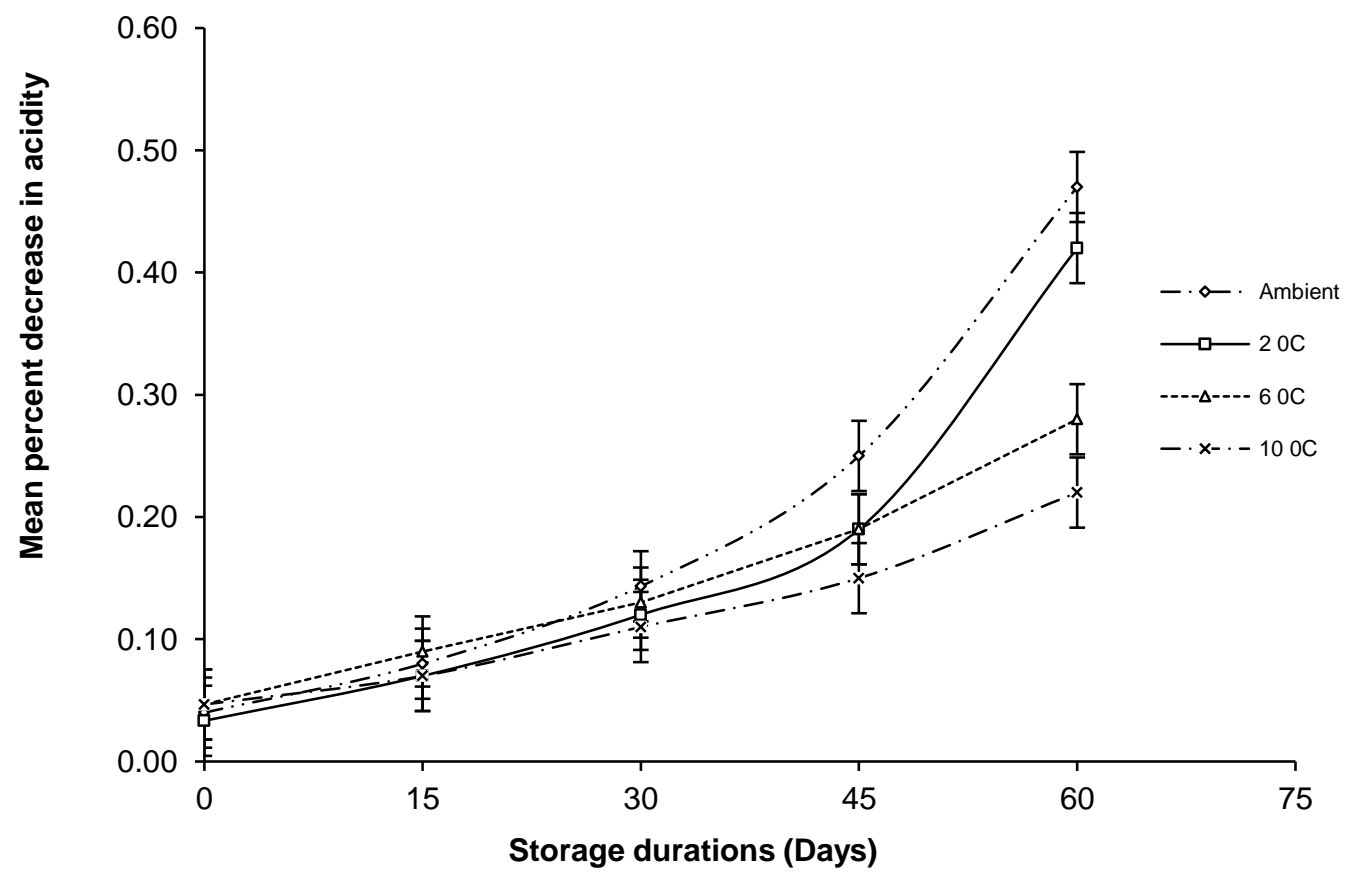

Figure 2. Mean percent decrease in acidity of oranges as affected different storage durations and temperatures during shelf life Table 1. The storage temperatures and durations effects on physico-chemical changes in oranges (after 72 hours simulated marketing) 


\begin{tabular}{|c|c|c|}
\hline Storage Duration (Days) & $\begin{array}{l}\text { Decrease in Ascorbic Acid } \\
(\mathrm{mg} / 100 \mathrm{~g})\end{array}$ & Decrease in acidity \\
\hline $\mathbf{0}$ & $0.04 \mathrm{e}$ & $0.04 \mathrm{e}$ \\
\hline 15 & $0.09 \mathrm{~d}$ & $0.08 \mathrm{~d}$ \\
\hline 30 & $0.17 \mathrm{c}$ & $0.13 \mathrm{c}$ \\
\hline 45 & $0.30 \mathrm{~b}$ & $0.20 \mathrm{~b}$ \\
\hline 60 & $0.65 \mathrm{a}$ & $0.35 \mathrm{a}$ \\
\hline LSD at $\alpha 0.05$ & 0.0387 & 0.0143 \\
\hline \multicolumn{3}{|l|}{ Storage temperature } \\
\hline Ambient condition & $0.45 \mathrm{a}$ & $0.20 \mathrm{a}$ \\
\hline $2^{\circ} \mathrm{C}$ & $0.22 \mathrm{~b}$ & $0.17 \mathrm{~b}$ \\
\hline $6^{\circ} \mathrm{C}$ & $0.17 \mathrm{c}$ & $0.15 \mathrm{c}$ \\
\hline $10^{\circ} \mathrm{C}$ & $0.15 \mathrm{c}$ & $0.12 \mathrm{~d}$ \\
\hline LSD at $\alpha 0.05$ & 0.0346 & 0.0128 \\
\hline \multicolumn{3}{|c|}{ Interaction (Storage temperature $\mathbf{X}$ Storage durations) } \\
\hline Significance & $*$ & $*$ \\
\hline LSD & 0.0774 & 0.0287 \\
\hline Figs & 1 & 2 \\
\hline
\end{tabular}

Means having similar letter(s) in columns do not significantly differ $\mathrm{NS}=$ non-significant and $*=$ Significant at $5 \%$ probability level

\section{Conclusion}

It is concluded that oranges could be kept in cold storage conditions for 45 days and further storage deteriorates quality resulting. Nevertheless, oranges can be kept for longer durations at $10^{\circ} \mathrm{C}$.

\section{Authors' contributions}

Conceived and designed the experiments: I Hussain \& A Rab, Performed the experiments: I Hussain, Analyzed the data: SM Khan, K Naveed \& S Ali, Contributed materials/ analysis tools: I Hussain \& M Sajid, Wrote the paper: I Hussain \& AUR Khan.

\section{References}

1. Lee SK\& Kader AA. (2000). Post Biol \& Tech 20: 207-220.

2. Tripoli E, Guardia MA, Giammanco S, Majo DD \& Giammanco $M$ (2007). Citrus flavonoids: Molecular structure, biological activity and nutritional properties: A review. Food Chemistry 104: 466-479.

3. Wang YC, Chuang YC \& Hsu HW (2007). The flavonoid, carotenoid and pectin content in peels of citrus cultivated in Taiwan. Food Chemistryin press.

4. Fotouhi R \& Fattahi J (2007). Citrus Growing in Iran. University of Guilan PressIran 305.

5. Gardner PT, White TAC, McPhail DB \& Duthie GG (2000). The relative contributions of vitamin $\mathrm{C}$, carotenoids and phenolics to the antioxidant potential of fruit juices. Food Chemistry 68: 471474.

6. Arena E, Fallico B \& Maccarone E (2001). Evaluation of antioxidant capacity of blood orange juices as influenced by constituents, concentration process and storage. Food Chemistry 74: 423-427.

7. Rapisarda $\mathrm{P}$, Bellomo SE \& Intrigliolo $\mathrm{F}$ (2001). Anthocyanins in blood orange: Composition and biological activity. Recent Research Development in Agricultural and Food Chemistry 5: 217-230.

8. PHDB (2008). Pre-feasibility study cold storage. Pakistan Horticulture Development and Export Board. 
9.Tariq MA, Tahir FM, Asi AA \& Pervez MA (2001). Effect of controlled atmosphere storage on damaged citrus fruit quality. International Journal of Agriculture and Biology 3: 9-12

10. Mutari A\& Debbie R (2011). The effects of postharvest handling and storage temperature on the quality and shelf of tomato. Afr J Food Sci 5(7): 446 - 452.

11. Ceponis MJ, Cappellini RA \& Lightner GW (1985). Disorders in crisp head lettuce shipments to the New York market, 1972-1984. Plant Disease 69:1016-1020.

12. Wissanee S \& Renu P (2007). Physical, Chemical and Microbiological Changes during Storage of Orange Juices cv. Sai Nam Pung and cv. Khieo Waan in Northern Thailan. International Journal of Agriculture and Biology15608530/2007/09-5-726-730.

13. AOAC (1990). In: K. Elrich (Ed.), Vitamin C (ascorbic acid) in vitamin preparations and juices. (pp. 10581059). Arlington, VA: Association of Official Analytical Chemists, Inc.
14. ShahidMN \& Nadeem AA (2011). Effect of bee wax coatings on physiological changes in fruits of sweet orange cv. Blood Red. Sarhad J Agric (27)3: 385394.

15. Abbasi NA, Iqbal Z, Maqbool M \&HafizIA (2009). Postharvest quality of mango (Mangifera indica) fruit as affected by chitosan coating. Pak J Bot 41: 343-357

16. Prabha A, Sharma HR, Goel AK \& Ranjana V (2006). Changes in ascorbic acid content of lemon fruits stored in zero energy cool chamber and under ambient atmosphere. Asian Journal of Dairy and Food Research 25 (1): 73-75.

17. Mbogo GP, Mubofu EB \& Othman OC (2010). Post-harvest changes in physical chemical properties and levels of some inorganic elements in off vine ripened oranges (Citrus sinensis) fruits cv Navel and Valencia of Tanzania".Afri $J$ Biotech 9 (12): 1809-1815.

18. Jan I, Rab A \& Sajid M (2015). Influence of calcium chloride on storability and quality of apple fruits. Pak J Agri Sci 52(1): 115-122. 